\title{
EFECTO DE LA FERTILIZACIÓN NITROGENADA SOBRE UNA COMPOSICIÓN BOTÁNICA CON TRÉBOL BLANCO (Trifolium repens) EN CAYAMBE - PICHINCHA
}

* Carlos Texán Ch.

** Freddy Daquierdo

\section{INTRODUCCIÓN}

El uso de fertilización técnica se inició con la introducción de especies forrajeras altamente productivas, la creciente utilización de fertilizantes se debe entre otros al acelerado agotamiento de la fertilidad de los suelos, debido a prácticas agronómicas inadecuadas que facilitaron el desgaste erosionando el contenido nutricional. La creciente demanda de alimento para los animales, mas los costos elevados de insumos y de la tierra, han obligado al productor pecuario a ser más eficiente en la producción de alimento. También se puede considerar que los sistemas de explotación intensiva utilizados en países como Nueva Zelanda, Estados Unidos y Holanda, están sirviendo como modelo de producción en nuestro país, realizando manejos más técnicos tanto en producción alimenticia como en el manejo de los animales y otros recursos.

La investigación consiste en determinar en qué porcentaje afecta la fertilización nitrogenada al desarrollo de una especie de leguminosas, sabiendo que una característica importante de estas plantas es el de actuar en simbiosis con bacterias que asimilan el nitrógeno atmosférico y fijar a las raíces de la planta para que aprovechen y se desarrollen mejor. La pastura a utilizar presenta una composición botánica de leguminosas $53.6 \%$, Trifolium repens (trébol blanco) y gramíneas $23.7 \%$, Dactylis glomerata, L.(pasto azul), malezas (Amaranthus retroflexus, Rumex orispus), $12 \%$, vacíos $5,76 \%$, materia muerta $4,89 \%$. Las dosis de fertilizante utilizado determinarán durante el transcurso de la investigación hasta qué punto afectan en forma positiva o negativa las aplicaciones nitrogenadas al Trifolium repens (trébol blanco) en base a Urea $(46 \% \mathrm{~N})$, así como determinar los costos de producción, y los aspectos negativos que puede ocasionar al suelo con las dosis aplicadas en determinado tiempo. \section{Trébol Blanco \\ Trifolium repens \\ Ciclo evolutivo: perenne \\ Crecimiento: rastrero \\ Uso: pastoreo}

ANÁLISIS PRELIMINAR DE INFORMACIÓN BÁSICA DISPONIBLE

Altitud: 1400 a 4200 msnm.

Rango de pH: 4.5 a 8.3

Rango de $T^{\circ}$ : 4 a $21^{\circ} \mathrm{C}$.

Clima: subcálido, templado y frío

Región: interandina

Precipitación: 300 a 2100 mm/año

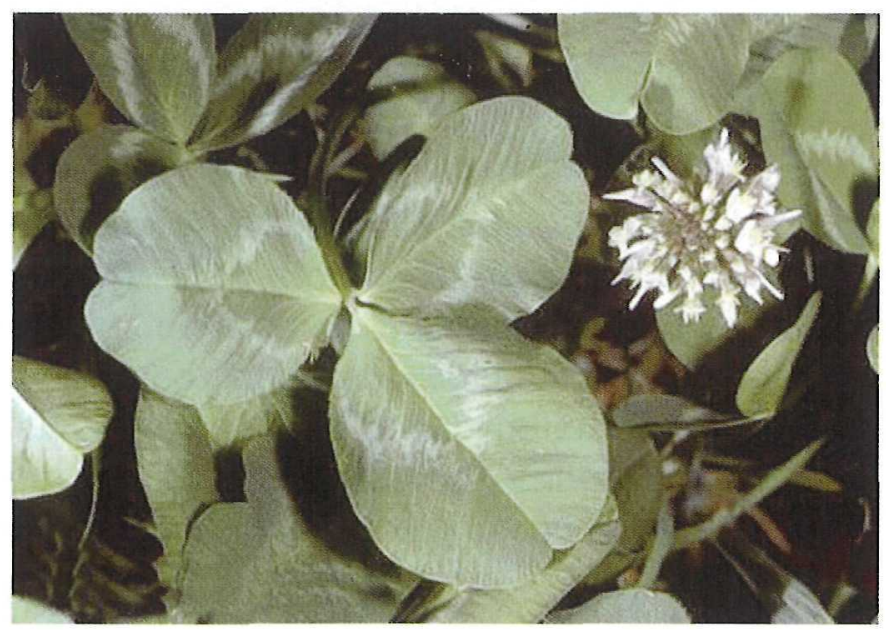




\section{Tolerancia a:}

- sequía: regular

- anegamiento: mala

- heladas: muy buena

- suelos poco fértiles: buena

- pastoreo: buena

- fertilización N: mala (perjudica la simbiosis de rizobios con la raíz de la planta)

- fertilización P: muy buena

- fertilización K: muy buena

Reproducción: sexual (semillas)

Siembra: voleo solo 10 a $20 \mathrm{~kg} / \mathrm{ha}$.

Mezcla: 5 a $8 \mathrm{~kg} / \mathrm{ha}$.

Manejo: fertilización con fósforo, potasio y materia orgánica

Producción Ha: 15 a 25 ton/año.

Cortes: 9 a 12

Carga animal: 3.5 a 5 UBA/ha.

Observaciones: palatable. Rico en proteína

Proteína: $28.1 \%$

Energía: $3518 \mathrm{kcal} / \mathrm{kg}$.

\section{EL NITRÓGENO EN LAS PLANTAS}

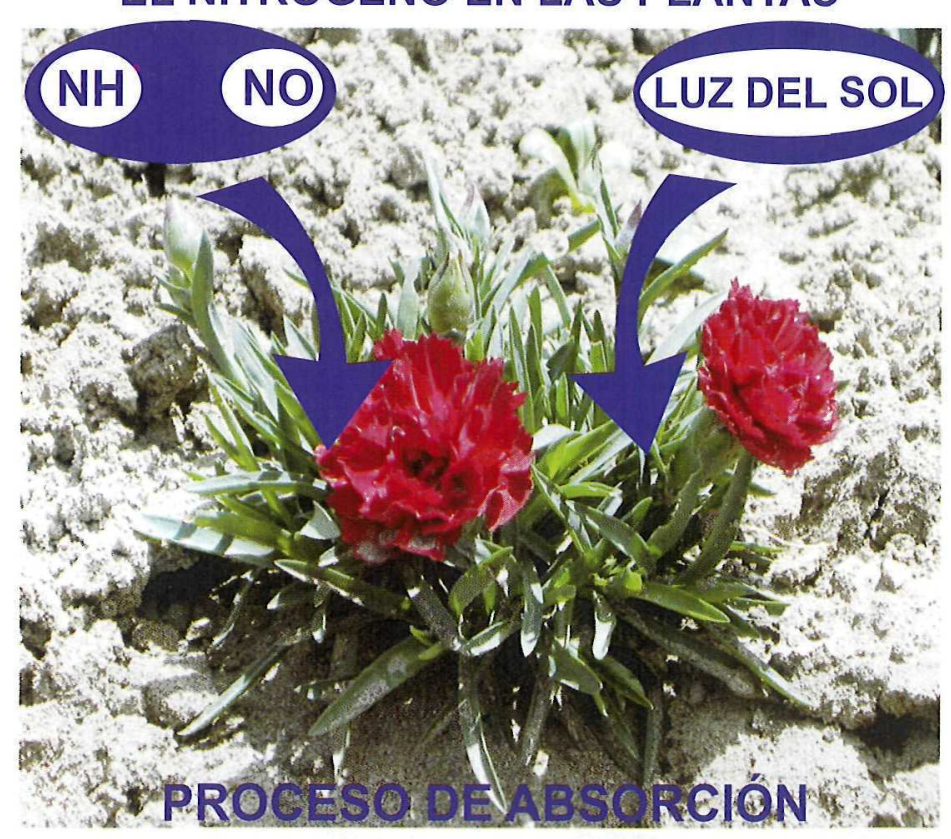

\section{Nitrógeno}

El nitrógeno $(N)$ es esencial para el crecimiento de las plantas, forma parte de todas las células vivas. Las plantas absorben la mayor parte del nitrógeno en la forma de iones de amonio (NH) o de nitrato (NO). La absorción directa de urea puede ocurrir a través de las hojas y pequeñas cantidades de $\boldsymbol{N}$ son obtenidas de ciertos materiales como aminoácidos solubles en agua.

El $\mathbf{N}$ es necesario para la síntesis de la clorofila y, como parte de la molécula de clorofila, tiene un papel en el proceso de fotosíntesis. La falta de $\mathbf{N}$ y clorofila significa que no utilizará la luz del sol como fuente de energía para llevar a cabo funciones esenciales como la absorción de nutrientes. El $\boldsymbol{N}$ es también un componente de las vitaminas y sistemas de energía de la planta; es considerado como el constructor de proteínas de las plantas en forma directa. Cantidades adecuadas de potasio y fósforo, especialmente el K, mejoran el uso que las plantas hacen de dosis altas de nitrógeno para la obtención de proteínas. 


\section{EL NITRÓGENO EN EL AIRE Y EL SUELO}

La cantidad de $\boldsymbol{N}$ en el suelo en forma disponible es pequeña. Muy poco se encuentra en las rocas y minerales que dieron origen al suelo. La mayoría del $\mathbf{N}$ del suelo proviene de la atmósfera terrestre, la que contiene cantidades ilimitadas. Cerca del $80 \%$ del aire que respiramos es $\mathbf{N}$, que debe combinarse con otros elementos antes de ser utilizado por las plantas. El $\mathbf{N}$ que se presenta en el suelo lo hace en tres formas:

1) Nitrógeno orgánico.- Parte de la materia orgánica del suelo, pero no está disponible para las plantas en crecimiento.

2) Nitrógeno amoniacal.- Está fijado en minerales arcillosos, se encuentra disponible para las plantas en forma de NH3.

3) lones de amonio y nitrato o compuestos solubles.- Este es el $\mathbf{N}$ que las plantas utilizan para su nutrición.

\section{FIJACIÓN DEL NITRÓGENO}

Cuando el $\mathbf{N}$ atmosférico se combina con el hidrógeno o el oxígeno, ocurre un proceso llamado "fijación". Este proceso debe ocurrir antes de que el $\mathbf{N}$ sea usado por las plantas. La fijación ocurre de diferentes formas:

BIOLÓGICA.- Puede ser simbiótica o no simbiótica. La fijación simbiótica del $\mathbf{N}$, se refiere a microorganismos que lo fijan y mientras crecen en asociación con una planta huésped, beneficiando a ambos (organismos-planta).

Por las bacterias de las leguminosas.- Las leguminosas se consideran cultivos mejoradores, gracias a la propiedad de fijar directamente el nitrógeno del aire. Esta fijación se debe a la presencia de una bacteria, el Bacillus radicicola o Rizobium, en los pequeños abultamientos (nudosidades) de las raíces de las leguminosas. Se dice que los dos organismos viven en simbiosis: el Bacilos radicola fija el nitrógeno del aire y se lo suministra a la leguminosa; y esta proporciona a la bacteria el carbono que necesita.

Por los azotobacters.- La fijación de nitrógeno por las bacterias aisladas es obra de dos especies principales:

- Anaerobia, poco importante, clostridium pasteuriarum.

- Aerobia, mucho más importante: azotobacter.

Los azotobacters se encuentran en gran número en los suelos bien aireados, convenientemente provistos de materia orgánica y de ácido fosfórico. El nitrógeno fijado en el cuerpo de los azotobacters sufre la nitrificación después de su muerte; el ejemplo más conocido es la asociación entre las bacterias Rizobium y las raíces de las leguminosas. Las bacterias forman nódulos en las raíces de las plantas, estos nódulos fijan $\boldsymbol{N}$ de la atmósfera haciéndolo disponible para la leguminosa, la cual en cambio contribuye con hidratos de carbono que proporcionan energía a los nódulos, fijando así el nitrógeno. 
La fijación simbiótica del $\mathbf{N}$ por parte de las bacterias de las leguminosas es considerada la fuente de $\mathbf{N}$ natural más importante para el suelo. Las investigaciones están tratando de encontrar organismos fijadores de $\mathbf{N}$, que crezcan en forma independiente y los fijen $\mathbf{N}$ en las no leguminosas.

El fósforo y el potasio afectan la nodulación y por lo tanto la fijación de $\mathbf{N}$, ya que aumentan el número de nódulos, el porcentaje de $\mathbf{N}$ y la producción de proteínas en la semilla. La fijación no simbiótica, realizan las bacterias que viven independientes en el suelo. La cantidad de $\mathbf{N}$ fijada por estos organismos es mucho menor que la cantidad fijada simbióticamente. La mayoría de las estimaciones indican que hasta $20 \mathrm{~kg} / \mathrm{ha} 0$ más son fijados anualmente por bacterias de vida independiente.

OXIDACIÓN NATURAL.- El calor generado por los relámpagos hace que el oxígeno reaccione con el $\mathbf{N}$ en el aire, formando luego $\mathbf{N}$-nítrico. La lluvia y la nieve agregan solamente alrededor de 6 a $10 \mathrm{~kg}$ de $\mathbf{N} / \mathrm{ha}$ promedio por año.

INDUSTRIAL.- Los procesos industriales fijan $\mathbf{N}$ eficazmente en formas disponibles para las plantas. El proceso más importante sintetiza amoniaco $(\mathbf{N H})$, a partir de $\mathbf{N}$ y el $\boldsymbol{H}$, en la forma siguiente: $\boldsymbol{N}+3 \boldsymbol{H}=2 \boldsymbol{N} \boldsymbol{H}$, el $\boldsymbol{H}$ es generalmente obtenido del gas natural. El $\mathbf{N}$ proviene directamente del aire.

\section{OBJETIVOS}

\section{Objetivo General:}

- Evaluar el comportamiento del trébol blanco (Trifolium repens) a diferentes dosis de fertilización nitrógenada.

\section{Objetivos específicos:}

- Analizar la composición botánica de la mezcla antes y después de la aplicación de las dosis de fertilización nitrogenada.

- Observar la respuesta de la mezcla forrajera luego de cada fertilización nitrogenada.

- Observar hasta qué punto la fertilización nitrogenada afecta en el crecimiento y desarrollo del trébol.

\section{a) Clima}

- Temperatura promedio anual: $14^{\circ} \mathrm{C}$

- Temperatura máxima: $26.4^{\circ} \mathrm{C}$

- Temperatura mínima: $5^{\circ} \mathrm{C}$

- Precipitación media anual: $895.7 \mathrm{~mm}$.

- Humedad relativa mínima: $20 \%$

- Humedad relativa máxima: $82 \%$

- Heleofanía: 10 a 12 horas sol.

- Velocidad viento: 36 km/hora.

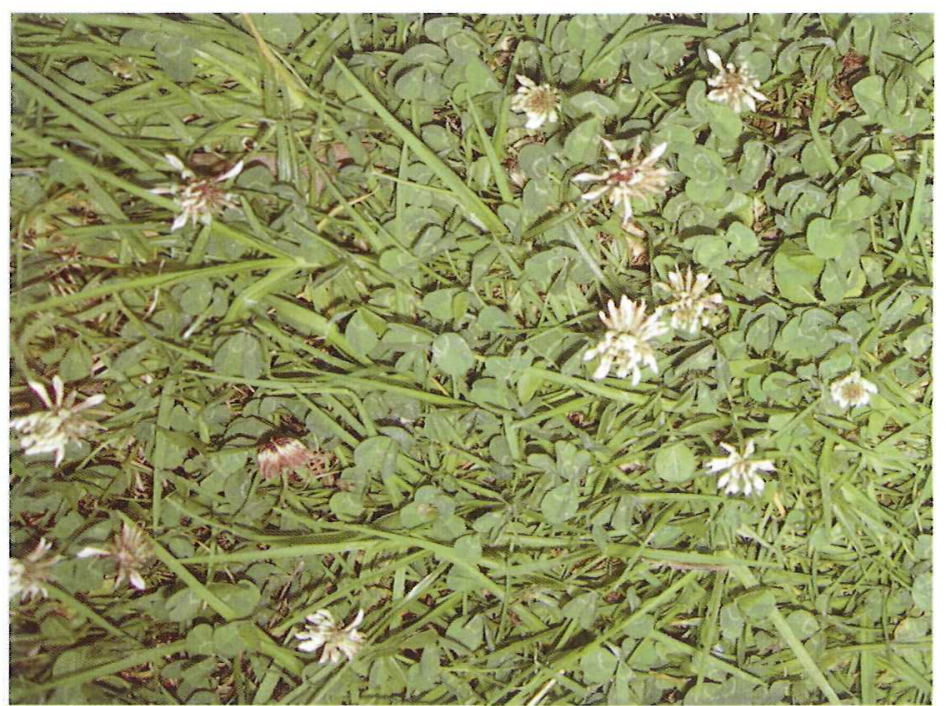


b) Suelo

De acuerdo al análisis de suelos se definen los siguientes parámetros:

$-p H^{* *}$ :

6.8

- Contenido de $N^{* *}(\mathrm{NH}): 45 \mathrm{ppm}$

- Contenido de $P^{* *}: 22$ ppm

- Contenido de $K^{* *}$ : 0,45 meq/100ml

- Contenido de $S^{* *}$ : 3,46 ppm

- Contenido M.O**: $3 \%$

- Declive: plano

- Drenaje: muy bueno

- Textura suelo**: F-A

- Profundidad capa arable: $45 \mathrm{~cm}$

- Profundidad raíces de plantas: 5 a $15 \mathrm{~cm}$

- Establecimiento: 1 año

Hipótesis alternativa (a).- En la investigación se obtienen tratamientos diferentes (T0 T1 T2 T3), lo que indica que las dosis de fertilizante nitrogenado aplicado tiene significancia, en rendimiento en materia seca, corte y en la composición botánica.

\section{PROCEDIMIENTO ESTADÍSTICO}

Tipo de diseño experimental.- Se utiliza un diseño de bloques al azar (DBCA).

Tratamientos.- La investigación consta de cuatro tratamientos, a los mismos que se les asigna cuatro repeticiones por cada uno. La codificación y su descripción es:

TO $=$ Tratamiento testigo, al que no se aplicará fertilizante nitrogenado.

T1 $=$ Tratamiento con aplicación de $150 \mathrm{~kg} \mathrm{~N} / \mathrm{ha} /$ año.

T2 = Tratamiento con aplicación de $200 \mathrm{~kg} \mathrm{~N} / \mathrm{ha} /$ año.

T3 $=$ Tratamiento con aplicación de $250 \mathrm{~kg} \mathrm{~N} / \mathrm{ha} /$ año.

\section{BIBLIOGRAFÍA}

1) TERRANOVA Editores Producción Agrícola 2, Tomo 3, Capítulo Pastos, pág. 381-383

2) DESDE EL SURCO Pastos y pastoreo, $2^{\circ}$ edición, pág. 85.

3) ABONOS NUTRIMON, Fertilización de cultivos de clima frío, $1^{\circ}$ edición 1988, págs. 10-18, 157-174.

4) COOKE G.W. Fertilizantes y sus usos, pág. 126-127.

5) AGROMARKET \# 2, DAVALOS G.: Manejo y establecimiento de pastos y praderas, pág. 20-23.

6) Manual de fertilidad de los suelos. Capítulo 3 (Nitrógeno), págs; 24-32.

7) BERTSCH F.: La fertilidad de los suelos y su manejo. ACCS San José Costa Rica 1998, págs. 73-82.

8) GROS, André: Guía práctica de la fertilización, $4^{\circ}$ edición, Capítulo VI EI nitrógeno, págs. 118-152.

9) RUSSELL E.W.: Soil conditions and plant growth (Condiciones del suelo y crecimiento de la planta), $10^{\circ}$ edición, ciclo en el suelo, págs. 327-387 y Nitrógeno, págs. 619-628.

* Tesista de ingeniería agropecuaria - Cayambe

** Catedrático de pastos y forrajes. Director de tesis. 